\title{
Asperities on the Surface of Plate-like Alumina and their Effect on Nacre-inspired Alumina-PMMA Composites
}

\author{
Bo-Yeon Kim****, Yoonjoo Lee*, Soo-Ryong Kim*, Dong-Geun Shin*, Woo-Teck Kwon*, \\ Duck-Kyun Choi**, and Younghee Kim**† \\ *Energy Efficient Material Team, Korea Institute of Ceramic Engineering and Technology, Jinju 660-031, Korea \\ ${ }^{3}$ Division of Materials Science and Engineering, Hanyang University, Seoul 133-791, Korea
}

(Received June 22, 2015; Revised July 13, July 22, 2015; Accepted July 22, 2015)

\begin{abstract}
Natural materials often have unique mechanical properties, such as the hierarchical structure of nacre formed through mineral bridges or asperities created between an inorganic particle and a natural-layer surface. As these asperities produce an exceptional shear resistance, in this study, we aimed to emulate the natural structure of nacre by synthesizing inorganic asperities and mineral bridges with different temperatures in the range of $1100-1300^{\circ} \mathrm{C}$ and clay contents from $10-50 \mathrm{wt} \%$. Following the infiltration of methyl methacrylate, we measured the mechanical properties to assess whether they were improved by the asperities. It was confirmed that the asperities improved the bending strength by $10 \%$, and the anchoring effect was observed on the fracture surface.
\end{abstract}

Key words : PMMA, Composite, Asperity, Energy efficiency, Plate like Alumina

\section{Introduction}

C eramics are typically strong materials, but their inherent brittleness is a weakness that needs to be overcome if they are to be used as high-performance structural materials. One method through which this might be achieved is the biomimetic technique, which relies on the extensive research into natural materials that has been conducted over the last few decades ${ }^{1-3)}$ and can offer unique characteristics. For example, nacre consists of $95 \%$ layered aragonite $\left(\mathrm{CaCO}_{3}\right)$ and $5 \%$ elastic biopolymers such as chitin, lustrin, and silk-like protein; ${ }^{4)}$ this implies that although abalone shell is composed of only a single-crystal aragonite plate, it has excellent mechanical properties such as remarkable strength, low weight, and a toughness that is three orders of magnitude greater than that of monolithic aragonite. ${ }^{5}$ These mechanical properties can be attributed to the hierarchical arrangement of $\mathrm{CaCO}_{3}$ platelets, which creates mineral bridges or asperities between inorganic and organic layers that help ensure good adhesion between them. ${ }^{6,7)}$ The structure of nacre also leads to a high toughness, ${ }^{8)}$ as the organic layers markedly improve its ability to absorb energy during deformation, especially when they are strongly adhered to the aragonite plates. Thus, the surface roughness of individual layers (i.e., mineral bridges or asperities) plays a critical role in controlling shear at the organic/inor-

${ }^{\dagger}$ Corresponding author: Younghee Kim

E-mail : yhkokim@kicet.re.kr

Tel : +82-55-792-2621 Fax : +82-55-792-2759 ganic interface during load..$^{9-12)}$

Composites inspired by abalone shell have previously been fabricated using various methods, with many researchers focusing on the ordering of platelet particles. For instance, Kotov et al. used a layer-by-layer (LBL) method with clay or polyelectrolyte, ${ }^{13-15)}$ while other groups used self-assembly ${ }^{16)}$ and various other chemical and physical deposition methods. ${ }^{17,18)}$ Ritchie et al. studied the mineral bridges of abalone shell ${ }^{19)}$ and used a freeze-casting method with inorganic materials such as clay and hydroxyapatite to replicate them. The resulting composites confirmed that fracture behavior is improved by mineral bridges between ceramic plates.

This study aims to replicate the mineral bridges and/or asperities on the surface of calcium carbonate $\left(\mathrm{CaCO}_{3}\right)$ platelets by forming asperities out of clay on the surface of plate-like alumina particles. The formation of mineral bridges or asperities at various temperatures and clay contents is herein discussed in relation to how the interaction between alumina and asperities affects the mechanical properties of the final composite.

\section{Experimental Procedure}

Commercial alumina powder (RonaFlair ${ }^{\circledR}$ White Sapphire $\geq 99.0 \%, 7.0$ - $11.0 \mu \mathrm{m}$, Merck Performance Materials), which has a plate-like shape with 0.5 - $\mu$ m thickness, was used as the inorganic material, to which $10-50 \mathrm{wt} \%$ clay was added to form asperities. In this study, kaolinite was used. To create organic-inorganic composites, methyl methacrylate (MMA, 99\%) and a benzoyl peroxide (BPO) initiator were 
Table 1. Alumina/PMMA Composites with Clay Contents

\begin{tabular}{ccccccc}
\hline Sample Name of Composites & AP & CA-1 & CA-2 & CA-3 & CA-4 & CA-5 \\
\hline Clay (wt \%, Aluminum Silicate Nano Asperities) & 0 & 10 & 20 & 30 & 40 & 50 \\
\hline
\end{tabular}

purchased from Sigma-Aldrich.

\subsection{Formation of asperities on alumina particles}

A suspension of $\sim 500$-nm clay particles in ethanol was first prepared through ball milling for $12 \mathrm{~h}$, and then alumina powder was added to result in an alumina powder to clay ratio of 1:0.1 - 0.5 by weight. This mixture was then aged for $24 \mathrm{~h}$ while stirring to achieve good dispersion and then dried at $50^{\circ} \mathrm{C}$. The resulting powder was placed in an alumina crucible and heated at $1100-1300^{\circ} \mathrm{C}$ for $1 \mathrm{~h}$.

\subsection{Fabrication of composites}

MMA monomer (99\%, Aldrich) and a BPO (99\%, Aldrich) catalyst for polymerizing the MMA were used to formulate organic-inorganic composites. For this purpose, green bodies were first prepared from a mixture of alumina and different amounts of clay through uniaxial pressing under one ton of force and subsequent heat treatment at different temperatures. The green bodies were transferred into an MMA/ $\mathrm{BPO}$ solution to infiltrate the MMA and then dried at $45^{\circ} \mathrm{C}$ for 1 day. Finally, bio-mimetic composites were prepared using a two-step curing process for PMMA (polymethyl methacrylate), wherein the pressure was first maintained at $10 \mathrm{MPa}$ for $1 \mathrm{~h}$ at $100^{\circ} \mathrm{C}$ and then increased to $20 \mathrm{MPa}$ for $1 \mathrm{~h}$ at $200^{\circ} \mathrm{C}^{20,21)}$ The name of the composite sample is given in Table 1.

\subsection{Characterization}

The asperities formed were examined using field-emission scanning electron microscopy (FE-SEM, JEOL, JSM-6700F), X-ray diffraction (XRD, P/MAX 2200V/PC, Rigaku Corp., Cu target, $\mathrm{Ka}=1.54 \AA$ ) and transmission electron microscopy (TEM, TEM-4010, JEOL). The mechanical properties of the composites were measured through a three-point bending test with $25 \mathrm{~mm}$ support span and a cross-head speed of $0.5 \mathrm{~mm} /$ min in air at room temperature by using 5 specimens each of dimensions $50 \times 4 \times 2.5 \mathrm{~mm}$ (length $\times$ width $\times$ depth).

\section{Results and Discussion}

\subsection{Characterization of asperities}

A SEM image of the original alumina particles is shown in Fig. 1, which reveals that they have a clear surface and vary in size between 10 and $15 \mu \mathrm{m}$. Fig. 2 shows the effect of temperature on the formation of asperities using clay, which was added at $10 \mathrm{wt} \%$. Fig. 2 (a) corresponds to a heat-treatment temperature of $1100^{\circ} \mathrm{C}$, which results in clay particles being well dispersed over the alumina. From the figures, it is not difficult to distinguish the alumina from the clay particles, which were $1 \mu \mathrm{m}$ in size and well dispersed on the alumina surface. With an increase in temperature, the alumina-clay interface became indistinct, and it appeared as if the clay adheres better to the alumina surface by melting (Figs. 2 (b) and (c)).

Clays thermally decompose through dehydroxylation at $400-600^{\circ} \mathrm{C}$ and recrystallize above $800^{\circ} \mathrm{C}$ in general. ${ }^{22)} \mathrm{Sub}-$ sequently, a change in morphology can occur, which leads to an increase in the energy state at the edges and surface of the particle, and the clay asperities appear to melt and are

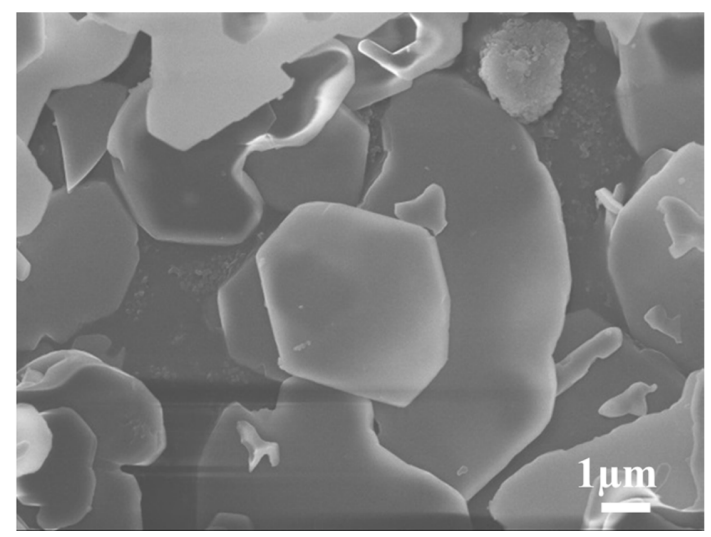

Fig. 1. SEM image of unmodified alumina particles.

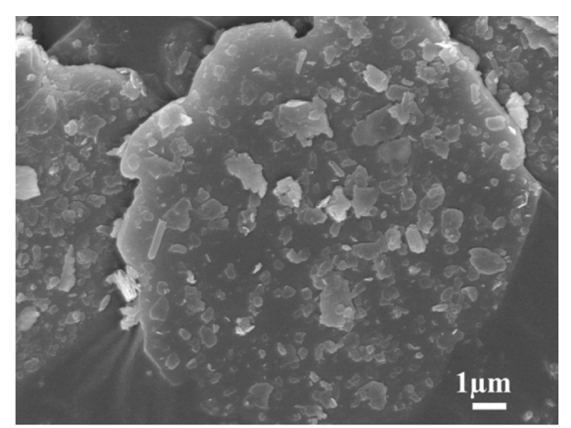

(a)

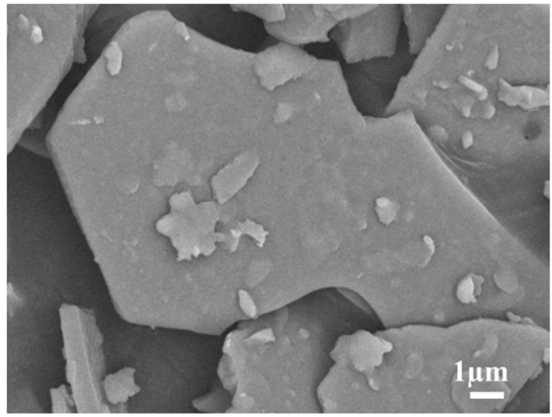

(b)

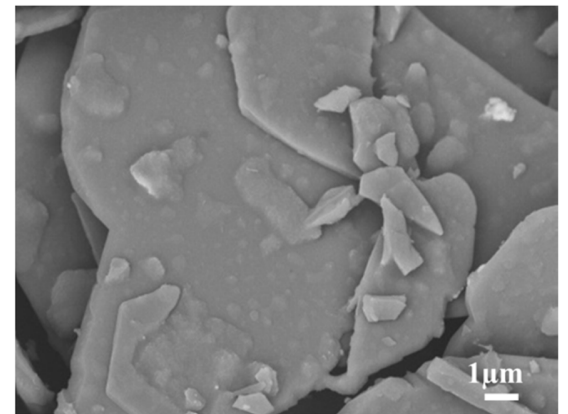

(c)

Fig. 2. SEM images of asperities formed through heat treatment at (a) $1100^{\circ} \mathrm{C}$, (b) $1200^{\circ} \mathrm{C}$, and (c) $1300^{\circ} \mathrm{C}$. 
attached on the alumina surface at $1200^{\circ} \mathrm{C}$ and $1300^{\circ} \mathrm{C}$. To verify the thermal effect on the formation of asperities, i.e., the correlation between the morphology and crystal structure, XRD spectra were obtained with different heat-treatment temperatures. The diffraction peaks at $1200^{\circ} \mathrm{C}$ are consistent with the presence of only alumina and mullite (Fig. 3(a)). However, as the temperature was increased to $1250^{\circ} \mathrm{C}$, a new peak appeared at a $2 \theta$ value of $21.5^{\circ}$ (Fig. 3 (b)), which is the main peak for silica (cristobalite), and it became stronger at $1300^{\circ} \mathrm{C}$ (Fig. 3(c)). Thus, it was confirmed that the asperities formed from the clay can be obtained as mullite or a mullite-silica mixture in the range of $1100-1300^{\circ} \mathrm{C}$. However, for better adhesion on the alumina surface, heat treatment must be performed at a temperature above $1200^{\circ} \mathrm{C}$, which is the lower limit on the reaction temperature required to obtain asperities.

The cross section of the microstructure of the composites was examined using TEM to identify the interface between the alumina particle and asperities more clearly. The focused ion beam (FIB) technique was used to prepare the samples. Fig. 4(a) shows that asperities (indicated by *) were formed on alumina, and the low-resolution TEM image in Fig. 4(b) clearly shows the boundary between the two. Note that the clay exists as aggregates of directional rod-like crystals; it can be seen that the asperities maintain the initial crystal direction of clay, which has a typical layered structure. Fig. 4(c) and (d) show the areas of close contact with the alumina surface. It is difficult to determine if chemical bonding occurs between the clay and alumina in these TEM images, but it can be confirmed that good adhesion is created between them.

\subsection{Fabrication of alumina-PMMA composites with different clay content}

The morphology of the asperities was confirmed to change according to the clay content, with clay contents less than 20 wt\% producing well-dispersed alumina particles (Fig. 5(a)). In contrast, when the clay content exceeded $30 \mathrm{wt} \%$, coarse-

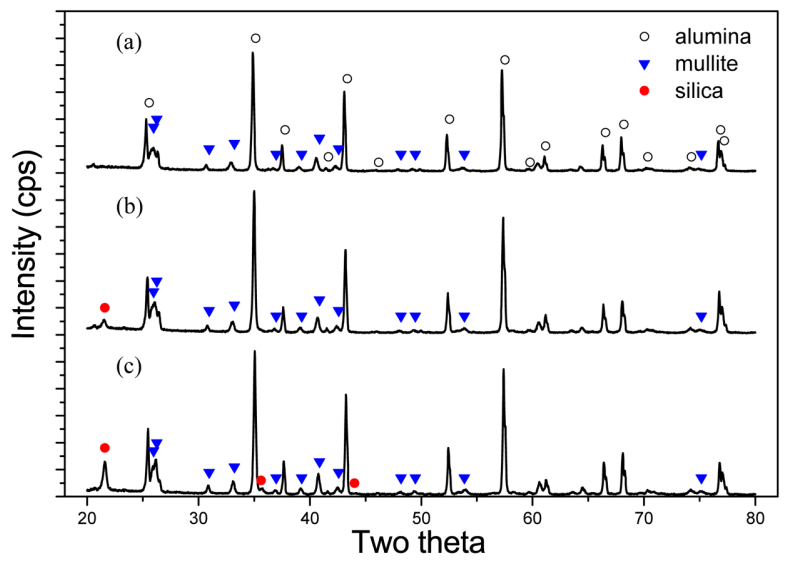

Fig. 3. X-ray diffraction patterns of samples heat treated at (a) $1200^{\circ} \mathrm{C}$, (b) $1250^{\circ} \mathrm{C}$, and (c) $1300^{\circ} \mathrm{C}$. grained particles or aggregations of alumina particles were obtained (Fig. 5(b)), which indicates that a high clay content can contact neighboring particles and build mineral bridges between alumina particles. Fig. 6(a) shows the fracture surface of the preform with $20 \mathrm{wt} \%$ clay, in which asperities can be seen on the alumina, whereas clay contents higher than $30 \mathrm{wt} \%$ formed mineral bridges between alumina particles (Figs. 6(c) and (d)). Following MMA infiltration and curing, asperities were observed to form among alumina particles without any void, as shown in Fig. 7. The PMMA content in the composite was measured to be $20 \mathrm{wt} \%$ through TG (thermo gravimetric) analysis.

\subsection{Effect of asperities on composite structure}

The mechanical properties of the bio-mimetic composites produced from alumina platelets with asperities were mea-

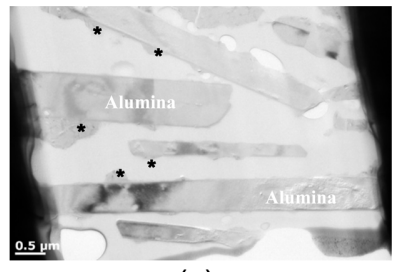

(a)

(c)

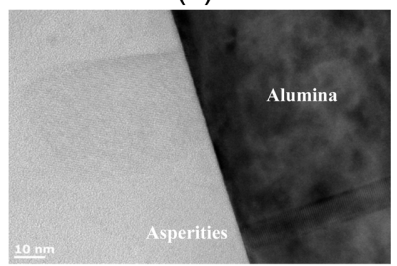

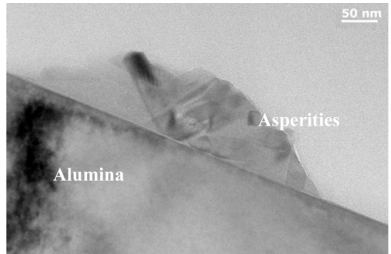

(b)

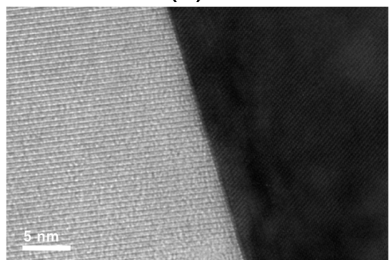

(d)
Fig. 4. (a) FIB-cut cross sections of a composite with clay (* indicates asperities). TEM images showing (b) aluminum-silicate nano asperities on the surface of alumina, (c) the crystallization of asperities, and (d) the alumina-asperity interface.
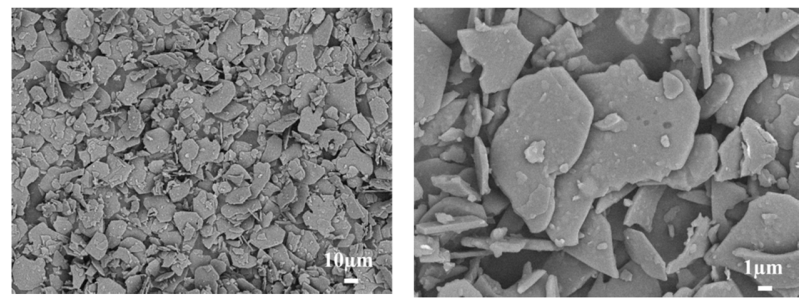

(a)
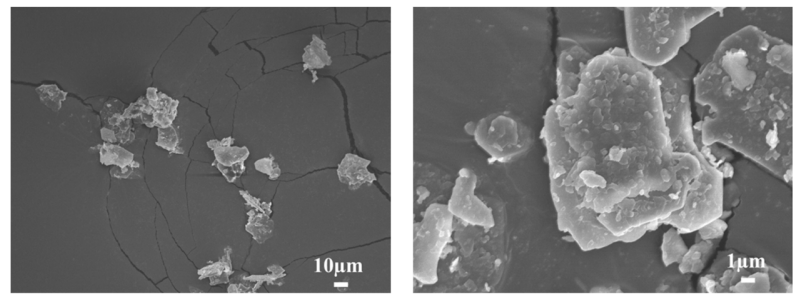

(b)

Fig. 5. SEM images of composites with clay contents of (a) $20 \mathrm{wt} \%$ and (b) $30 \mathrm{wt} \%$ 
sured using a three-point bending test. Note that the alumina/PMMA and alumina/PMMA with clay asperities are hereafter referred to as $\mathrm{AP}$ and $\mathrm{CA}$, respectively. The ultimate bending strength of AP was found to be $71.9 \mathrm{MPa}$, whereas that of CA-1 which was prepared with $10 \mathrm{wt} \%$ clay was increased by $10 \%$ or more up to $86.5 \mathrm{MPa}$. Similarly, increasing the clay content to $50 \mathrm{wt} \%$ increased the strength further to $98 \mathrm{MPa}$. Fig. 8 shows how the strength of alumina/PMMA changes with respect to the addition of clay asperities, from which it is clear that clay asperities increase the strength. However, considering the error range, clay contents in the range of $10-40 \mathrm{wt} \%$ were not effective.

In nature, the fracture behavior of nacre is explained by the pull-out behavior. ${ }^{7)}$ This means that the aragonite tablet does not break; rather, it just slides out from its initial position. Diverse factors in the resistance of the pull-out behavior has been discussed with the high strength of the nacre structure by many research groups, and one of factors was

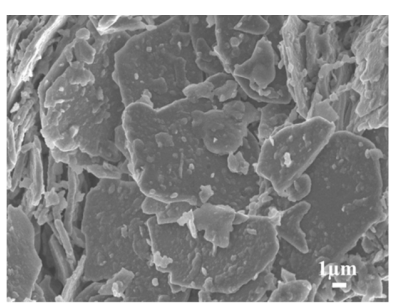

(a)

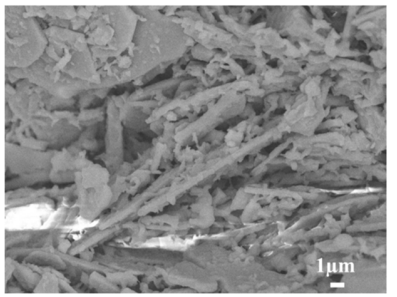

(c)

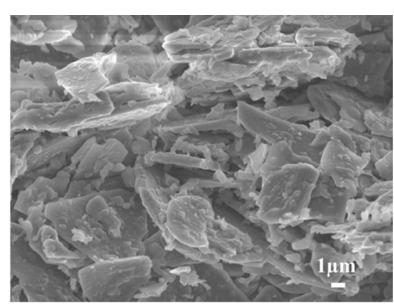

(b)

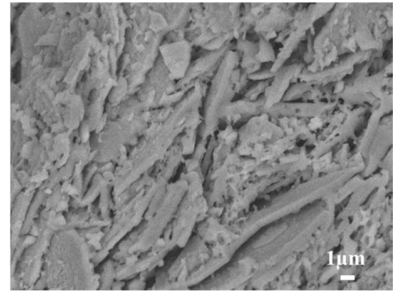

(d)
Fig. 6. Fracture surface of asperities produced with clay additions of (a) $20 \mathrm{wt} \%$, (b) $30 \mathrm{wt} \%$, (c) $40 \mathrm{wt} \%$, and (d) $50 \mathrm{wt} \%$ at $1200^{\circ} \mathrm{C}$.

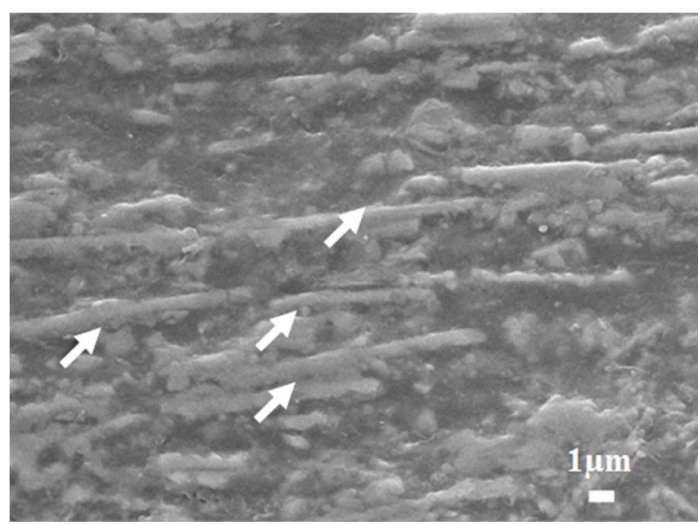

Fig. 7. Cross-sectional SEM images of composite consisting of alumina with asperities and 20 wt\% PMMA. the asperities. ${ }^{82-25)}$ The fracture surface of AP is shown in Fig. 9(a) with an arrow to distinguish between the alumina and PMMA. The alumina has a clear surface, and the PMMA shows a tearing shape indicating typical deformation behavior of the polymer. The empty areas that appear to be pores result from disappearing alumina particles, which is similar to the pull-out behavior in natural nacre.

Figure 9(b) shows the fracture surface of CA-2. It was confirmed that the asperities derived from clay remained on the alumina surface after the deformation of the composite, and its impression on the PMMA side was observed. Moreover, a tiny sign of tearing was just distinguishable, and it was quite different from the tearing in AP. We estimated that the asperities restrain alumina particles from sliding out from their original locations through the anchoring effect when the composite was fractured and that they consequently inhibited the PMMA and the adjacent alumina

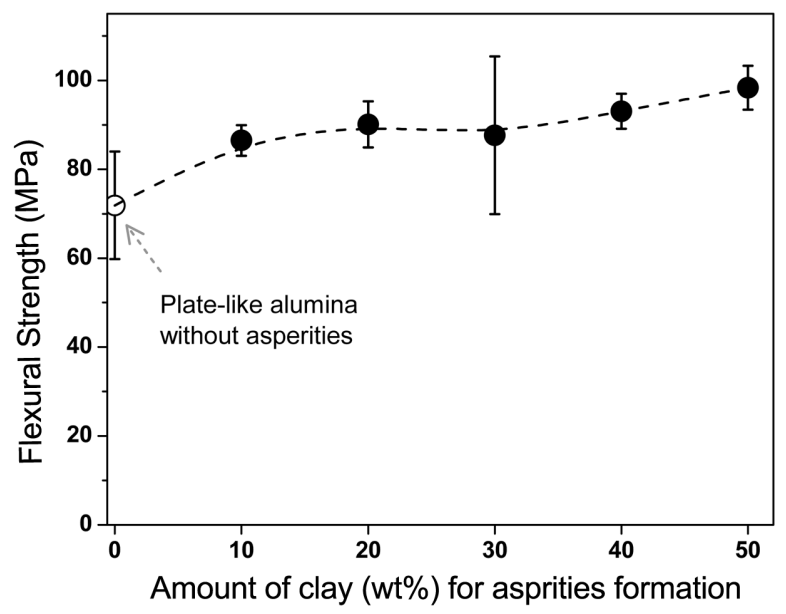

Fig. 8. Relationship between flexural strength and clay content of alumina with asperities/PMMA composite.
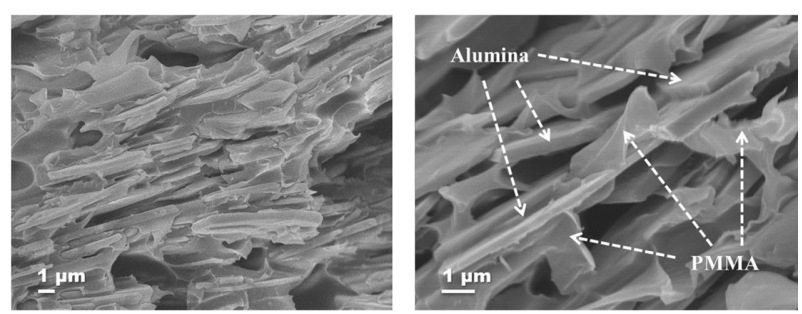

(a)
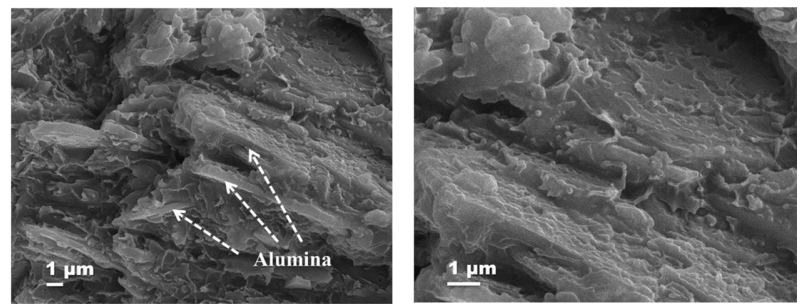

(b)

Fig. 9. Scanning electron micrographs showing the fracture surface of (a) alumina/PMMA composite and (b) alumina with asperities/PMMA composite. 
particles from extending through deformation. This evidences the effect of asperities on increasing the composite strength.

\section{Conclusions}

By attempting to replicate the nano asperities and mineral bridges of nacre shell using clay, it has been confirmed that clay particles undergo a phase transition to mullite and silica at temperatures above $1200^{\circ} \mathrm{C}$ and that the modified clay particles adhere well to the surface of alumina. The bending strength of an organic-inorganic composite made from alumina powder and PMMA (73 $\mathrm{MPa}$ ) was found to be increased with the addition of clay asperities (up to $98 \mathrm{MPa}$ with 50 wt\% clay addition), confirming that clay asperities improve the mechanical properties of the composite. This improvement is attributed to the adhering of the asperities to alumina platelets, which helps control shear at the organic/inorganic interface under load.

\section{Acknowledgments}

This research was supported by the Pioneer Research Center Program through the NRF (National Research Foundation of Korea) funded by the MSIP (Ministry of Science ICT \& Future Planning) (Grant No. 2011-0001682).

\section{REFERENCES}

1. C. Sanchez, H. Arribart, and M. M. G. Guille, "Biomimetism and Bioinspiration as Tools for the Design of Innovative Materials and Systems," Nat. Mater., 4 [4] 277-88 (2005).

2. A. A. AI-Munajjed, N. A. Plunkett, J. P. Gleeson, T. Weber, C. Jungreuthmayer, T. Levingstone, J. Hammer, and F. J. O’Brien, "Development of a Biomimetic Collagen-Hydroxyapatite Scaffold for Bone Tissue Engineering Using a SBF Immersion Technique," J. Biomed. Mater. Res., 90B [2] 584-91 (2009).

3. I. C. Gebeshuber, "Biotribology Inspires New Technologies," Nano Today, 2 [5] 30-37 (2007).

4. F. Song, A. K. Soh, and Y. L. Bai, "Structural and Mechanical Properties of the Organic Matrix Layers of Nacre," Biomaterials, 24 [20] 3623-31 (2003).

5. A. P. Jackson, J. F. V. Vincent, and R. M. Turner, "The Mechanical Design of Nacre," Proc. R. Soc. London, B Biol. Sci., 234 [1277] 415-440 (1988).

6. A. G. Checa, J. H. E. Cartwright, and M. -G. Willinger, "Mineral Bridges in Nacre," J. Struct. Bio., 176 [3] 330-39 (2011).

7. R. Z. Wang, Z. Suo, A. G. Evans, N. Yao, and I. A. Aksay, "Deformation Mechanisms in Nacre," J. mater. Res., 16 [9] 2485-93 (2001).

8. J. Y. Sun and B. Bhushan, "Hierarchical Structure and Mechanical Properties of Nacre: a Review," RSC Advances, 2 [20] 7617-32 (2012).

9. A. G. Evans, Z. Suo, R. Z. Wang, I. A. Aksay, M. Y. He, and J. W. Hutchinson, "Model for the Robust Mechanical Behavior of Nacre," J. Mater. Res., 16 [9] 2475-84 (2001).
10. J. Wang, Q. Chang, and Z. Tang, "Layered Nanocomposites Inspired by the Structure and Mechanical Properties of Nacre," Chem. Soc. Rev., 41 [3] 1111-29 (2012).

11. M. Sarikaya, K. E. Gunnison, M. Yasrebi, and I. A. Aksay, "Mechanical Property-Microstructural Relationships in Abalone Shell," MRS Proceedings, 174 109-16 (1989).

12. Y. J. Lee, B. Y. Kim, D. G. Shin, S. R. Kim, W. T. Kwon, and Y. H. Kim "Formation of Asperities on the Plate-Like Alumina Particles by Molten-Salt Method," J. Korean Ceram. Soc., 51 [6] 560-65 (2014).

13. N. A. Kotov, I. Dekany, and J. H. Fendler, "Layer-by-Layer Self-assembly of Polyelectrolyte-Semiconductor Nanoparticle Composite Films," J. Phys. Chem., 99 [35] 13065-69 (1995).

14. Z. Tang, N. A. Kotov, S. Magonov, and B. Ozturk, "Nanostructured Artificial Nacre," Nat. Mater., 2 413-18 (2003).

15. P. Podsiadlo, Z. Tang, B. S. Shim, and N. A. Kotov, "Counterintuitive Effect of Molecular Strength and Role of Molecular Rigidity on Mechanical Properties of Layer-by-Layer Assembled Nanocomposites," Nano Lett., 7 [5] 1224-31 (2007).

16. A. Sellinger, P. M. Weiss, A. Nguyen, Y. Lu, R. A. Assink, W. Gong, and C. J. Brinker, "Continuous Self-assembly of Organic-Inorganic Nanocomposite Coatings that Mimic Nacre," Nature, 394 256-60 (1998).

17. R. Chen, C. Wang, Y. Huang, and H. Le, "An Efficient Biomimetic Process for Fabrication of Artificial Nacre with Ordered-Nanostructure," Mater. Sci. Eng. C, 28 [2] 218-22 (2008).

18. Y. Zhang and J. R. G. Evans, "Alignment of Layered Double Hydroxide Platelets," Coll. Surf. A Physicochem. Eng. Asp., 408 71-78 (2012).

19. M. E. Launey, E. Munch, D. H. Alsem, E. Saiz, A. P. Tomsia, and R. O. Ritchie, "A Novel Biomimetic Approach to the Design of High-Performance Ceramic-Metal Composites," J. R. Soc. Interface, 7 [46] 741-53 (2010).

20. K. M. Nam, Y. J. Lee, W. T. Kwon, S. R. Kim, H. M. Lim, H. S. Kim, and Y. Kim, "Preparation of $\mathrm{Al}_{2} \mathrm{O}_{3}$ Platelet/PMMA Composite and its Mechanical/Thermal Characterization," J. Korean Ceram. Soc., 49 [5] 438-41 (2012).

21. K. M. Nam, Y. J. Lee, W. T. Kwon, S. R. Kim, D. G. Shin, H. M. Lim, H. S. Kim, and Y. Kim, "Bio-inspired Synthesis of a Silicate/PMMA Composite," J. Korean Ceram. Soc., 51 [1] 7-10 (2014).

22. Y. Sarikaya, M.Önal, B. Baran, and T. Alemdaroğlu, "The Effect of Thermal Treatment on Some of the Physicochemical Properties of a Bentonite," Clays and Clay Minerals, 48 [5] 557-62 (2000).

23. F. Barthelat, H. Tang, P. D. Zavattieri, C. -M. Li, and H. D. Espinosa, "On the Mechanics of Mother-of-Pearl: A Key Fracture in the Material Hierarchical Structure," J. Mech. Phy. Solids, 55 306-37 (2007).

24. M. A. Meyers, A. Y. -M. Lin, P. -Y. Chen, and J. Muyco, "Mechanical Strength of Abalone Nacre: Role of the Soft Organic Layer," J. Mech. Behav. Biomed. Mat., 1 [1] 76-85 (2008).

25. F. Barthelat, C. -M. Li, C. Comi, and H. D. Espinosa, "Mechanical Properties of Nacre Constituents and their Impact on Mechanical Performance," J. Mater. Res., 21 [8] 1977-86 (2006). 